\title{
A Systematic Literature Review of the Research on Traditional Medicine Policy
}

\author{
${ }^{1}$ WAYU EKO YUDIATMAJA, ${ }^{2}$ IMAM YUDHI PRASTYA, 33ELVI DIANA MEILINDA, \\ ${ }^{4}$ TRI SAMNUZULSARI
}

\footnotetext{
${ }^{1,2}$ Department of Public Administration, Faculty of Social and Political Sciences, Universitas Maritim Raja Ali Haji, Jl. Raya Dompak, Tanjungpinang, Kepulauan Riau, Indonesia

${ }^{3}$ Department of Public Administration, Faculty of Social and Political Sciences, Universitas Lampung,

Jl. Prof. Dr. Ir. Sumantri Brojonegoro No. 1 Gedong Meneng Raja Basa, Bandar Lampung, Lampung, Indonesia ${ }^{4}$ Department of Sociology, Faculty of Social and Political Sciences, Universitas Maritim Raja Ali Haji, Jl. Raya Dompak Tanjungpinang, Kepulauan Riau, Indonesia email: ${ }^{1}$ wayuguci@umrah.ac.id; ${ }^{2}$ yudhiimam@umrah.ac.id; ${ }^{3}$ selvi.meilinda@fisip.unila.ac.id; ${ }^{4}$ nuzulsari@umrah.ac.id
}

\begin{abstract}
The primary objective of this study is to explore the past and recent research in traditional medicine policy published by scholarly journals. From a series of reputable databases, including BMC, Cambridge, Elsevier, JSTOR, Sage, Science Direct, Springer, Taylor and Francis, and Wiley, one hundred fifty articles were collected for further analysis. Using a systematic literature review, evidence from this work shows that the predominance of traditional medicine policy research is developed from theory and empirical studies, using random sampling and qualitative analysis. There are a wide variety of subject matters studied, but the research commonly focuses on Asia, Africa, and Latin America. The future research directions in this area are discussed to address various theoretical, methodological, and empirical gaps from the prior research. This study positively contributes to our understanding of the development and trends of traditional medicine policy.
\end{abstract}

Keywords: literature review, systematic literature review, traditional medicine policy

\section{Introduction}

This study is a systematic literature review of the research on traditional medicine policy. The central aims of this study are to draw the development of the research of traditional medicine policy, the trends, and direction for future research. World Health Organization defined traditional medicine as the medicine coming from indigenous knowledge, theories, experiences, and beliefs, usually used to maintain human health and prevents disease (WachtelGalor \& Benzie, 2011). Traditional medicine is a cultural heritage handed down from generation to generation by the local people (Sackey \& Kasilo, 2010). Usually, traditional medicine, both its interventions and therapies, is highly excluded by the Western medical system (Hunter et al., 2017).

Traditional medicine has existed along with human civilization. Many societies around the globe have utilized herbal materials as a traditional medicine to heal from various diseases (Schulz et al., 2004). For instance, in Japan, there is Campo, traditional medicine formulas used as vitamins and pharmaceuticals (Saito, 2000). In Indonesia, Jamu, rooted in Javanese culture, has long been acknowledged as not only for medicine but also for health care, beauty care, and endurance (Elfahmi et al., 2014; Riswan \& Sangat-Roemantyo, 2002) jamu is still very popular in rural as well as in urban areas. Based on its traditional use jamu is being developed into a rational form of therapy, by herbal practitioners and in the form of phytopharmaceuticals. Jamu has acquired a potential benefit, both economically and clinically. We surveyed the most frequently used plants in jamu that have also been investigated regarding their

Received: June 10, 2020, Revision: October 26, 2020, Accepted: June 08, 2021

Print ISSN: 0215-8175; Online ISSN: 2303-2499. DOI: https://doi.org/10.29313/mimbar.v37i1.6264

Accredited Sinta 2 based on the decree No.10/E/KPT/2019 until 2024. Indexed by DOAJ, Sinta, Garuda, Crossreff, Dimensions 
constituents and pharmacological effects. The Indonesian government has divided the preparation of medicinal plants into three categories, i.e. jamu, standardized herbal medicines and fitofarmaka (phytomedicines.

Many governments around the world begin to concern about promoting traditional medicines. In line with the global trend "back to nature", the policymakers in many countries begin to pay attention to the development of traditional medicine. As a consequence, rapid progress in traditional medicine policy has occurred around the world. WHO (2019, p. 15) noted that 98 of its members had had a national policy on traditional medicine. The number increases twofold if it is compared to 2005, which are only 45 states. The policy is aimed to regulate various aspects of traditional medicine. These trends show that the growth of consciousness of the countries to protect and build their traditional medicines is in order to be an icon and economical product.

Research on the policy of traditional medicine is a part of the study in the area of policy studies. Policy studies involve a various spectrum of government activities in addressing public affairs (Weible, 2014). As a consequence, the scope of policy studies in accordance with the field of study is vast wide involving a large number of dimensions of public issues, such as energy, unemployment, taxation, economic growth, and including traditional medicine. Moreover, policy studies have been developed as an integrated discipline by incorporating various studies (Sabatier, 1991; Weimer, 2008).

Currently, because of its importance, traditional medicine is still used and believed by many societies. Although the use of biomedicine is still dominant, many studies have found that traditional medicine has been used by many people on different continents in the world. Societies still believe in the benefit of traditional medicine in human life. Liu et al. (2011) reviewed Traditional Chinese Medicine (TCM) used as a cancer treatment in China. They revealed that almost ninetynine percent of patients had used TCM for cancer treatment in China. Maroyi (2013) presented that there are 93 medicinal plants employed by the poor communities to resolve a series of diseases in Zimbabwe. In his study on Australian Aborigin, Oliver (2013) also showed that traditional medicine is utilized as complementary to biomedicine. By reviewing articles published before 2016,
Takayama et al. (2017) found that many people have been applied for traditional medicine to address trauma, post-traumatic stress disorder (PTSD), and other indications post-disasters.

There are several recent works of literature about the review of traditional or alternative or herbal medicine research conducted by the scholars (Cao et al., 2010; Eardley et al., 2012; Hall et al., 2012; Kamsu-Foguem \& Foguem, 2014; Li et al., 2013). However, many of the reviews were typically based on a medical perspective employing medical dimensions in exploring traditional medicine inquiries. The prior review focused on several medical features of traditional medicine policy, such as medical or diseases case and was limited to medical journals. Therefore, this study fills the gap in recent literature by reviewing the research on traditional medicine from the policy perspective. The policy perspective in this study is positioned as the issue of traditional medicine in the context of government regulation regarding the specific policy adjusting traditional medicine and policy mechanism controlling traditional medicine in certain countries (Konisky \& Teodoro, 2016).

The present study fills the gap in three ways. First, this study presents the review of the research results on the traditional medicine policy from 150 articles published in scholarly journals from 2010 to 2019. Second, this research answers three noteworthy questions, which are: (1) How is the research on traditional medicine policy? (2) What is the focus of the subjects in traditional medicine policy? and (3) What methodologies are being used? Finally, this study uses content analysis by systematically reviewing the literature related to traditional medicine policy.

This article is prepared in four sections as follows: the first section is an introduction containing the background and purpose of this study that includes the rationale of this study, the objective and the significance of the study. Methods of the study are drawn in the second section that discusses research methods, process of gathering data, and interpretation of the findings. The third section contains the results and discussion of the study based on several categories that will be shed light on. The last stage concludes the results of the paper. 


\section{Research Methodology}

For the research purpose, this paper defines the research of traditional medicine policy as all of the research articles related to the government policy of traditional medicine around the world, including both policy processes (formulation, implementation, and evaluation) and policy analysis (Yudiatmaja, 2012, 2016). A systematic literature review using PRISMA (The Preferred Reporting Items for Systematic Reviews and Meta-Analysis) was conducted to achieve the study's purpose. It was commonly employed to report a literature review and meta-analysis (Fink, 2014). The articles were gained from a reputable electronic database, both open and closed access, specifically BMC, Cambridge, Elsevier, JSTOR, Sage, Science Direct, Scopus, Springer, Taylor and Francis, and Wiley. The searching for electronic data from the databases was conducted by using the keywords "policy" and "traditional medicine." From search results, it generated 301 articles and eliminated 122 articles because of duplication or irrelevant content, so that it yielded 179 articles. From the number of articles, the articles further analyzed were 150 articles from 36 journals (see Figure 1 ).

In this study, following Fitzpatrick's et al. (2011) logic, the articles collected were coded as follows: (1) research type, including (a) article type (essays, research paper, and review paper), (b) research purpose (descriptive, explanative, explorative), and (c) the frameworks or perspective used (institutional, regulation, cultural); (2) the theory used, including (a) the article cited and developed an existing theory or not, and (b) the article investigated or enlarged or built a theory; (3) the main and secondary subjects of study; (4) the unit of analysis (organization, persons, policy); (5) methodological preferences, including (a) method of gathering data, (b) data sources, (c) technique of analysis, (d) sample size, and (e) logic of sample choice.

This study followed three steps. In the earlier phase, the articles related to the issue of traditional medicine policy were searched. A content analysis was conducted to analyze the articles (Elo \& Kyngäs, 2008; Hsieh \& Shannon, 2005). A series of coding was used to help in sorting out the articles. In the beginning, it was found 301 articles discussing traditional medicine policy, and 122 items were excluded because of inapplicability. 29 articles were further removed in order to rest only 150 articles. Then, the data gathered were analyzed using SPSS to perform the trends of the research and patterns in traditional medicine policy by time and by journals. The steps are as drawn in Figure 1.

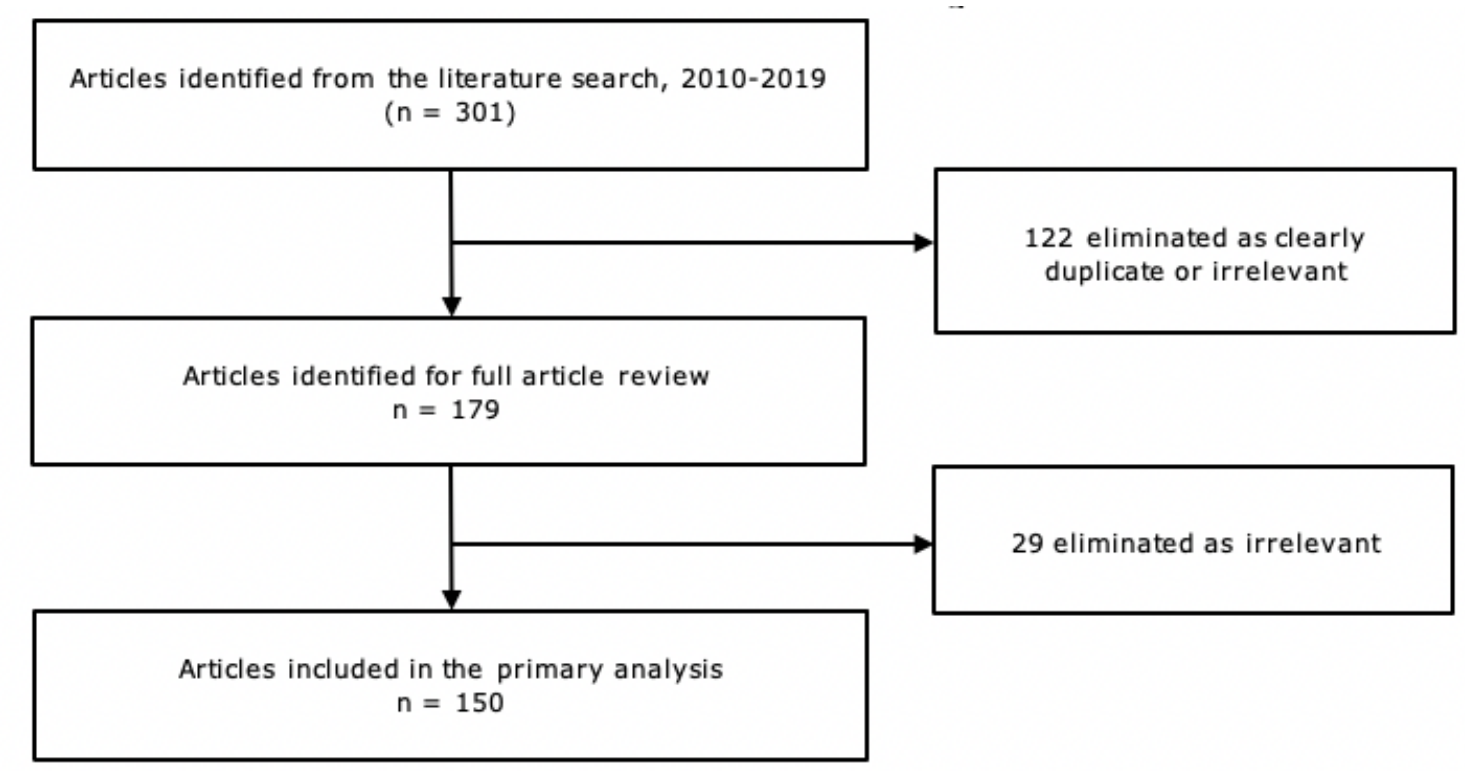

Figure 1. Identification of Related Articles

Note: The articles searched in the articles published from 2009 to 2019 with "policy" and "traditional medicine" terms in the title, keyword, and abstract. Book reviews, commentaries, or letters are excluded in the search criteria 


\section{Results and Discussion}

\section{Findings of Systematic Literature Review}

Graphic 1 presents a number of articles on traditional medicine policy and the total articles searched. It indicates that both various articles of traditional medicine policy and total articles fluctuate time by time. The highest articles on traditional medicine policy (25 articles) and a number of articles (28 articles) were published in 2015.

Firstly, the framework used by the scholars in the research of traditional medicine policy through investigating describes: (1) article type (essays, research paper, and review paper), (2) research purpose (descriptive, explanative, explorative), (3) frameworks or perspective used (institution, behavior, disease, medicine, and culture), (4) the use of theory, and (5) the subject and countries observed. The results are summarized in the following paragraphs.
Almost three in four (75 percent) of the articles investigated are research papers, called an article written from the empirical or fieldwork research. A 20 percent review paper is categorized as an article purposed to review various literature related to the issue. Typically, the review paper presents current research development in terms of subject matter, theory or framework, and methods in traditional medicine policy. As much as 5 percent is an essay-an article that employs secondary data mostly from previous journal articles to reanalyzing the data and find new conclusions.

This paper also examines the classification of the objective of the articles in such categories (i.e., descriptive, explorative, and explanative). The results find that most of them are explorative research articles (43 percent). Descriptive and explanative research articles only get about 42 percent and 13 percent out of 150 articles reviewed. Interestingly, there is only 2 percent of the

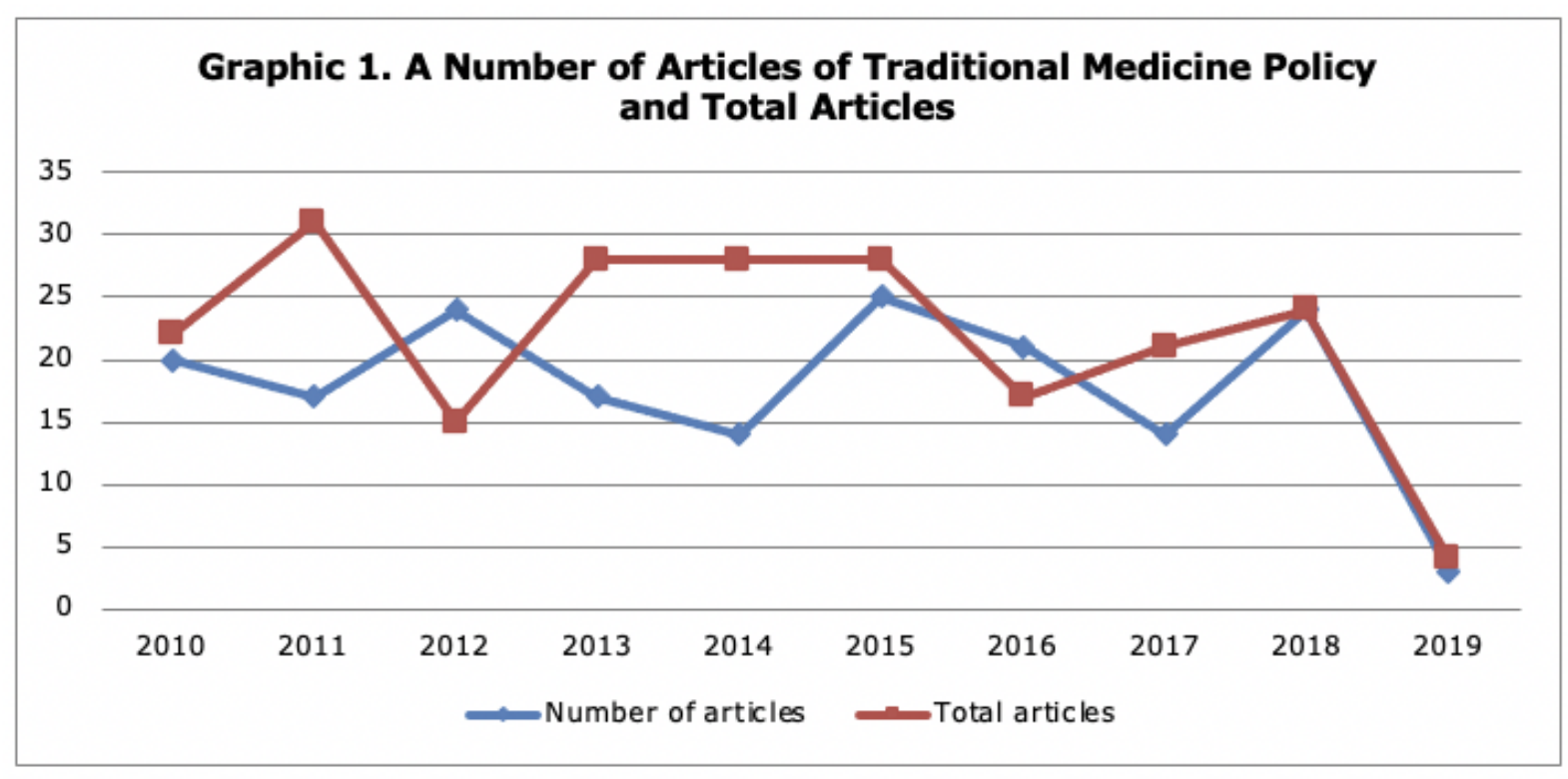

Table 1.

General Subjects Studied, 2009-2019 ( $n=150$ articles)

\begin{tabular}{lcc}
\hline Subject & Number & Percentage \\
\hline Attitudes and behavior & 15 & 10 \\
Barriers of traditional medicine & 5 & 3 \\
Characteristics of traditional medicine & 5 & 3 \\
Collaboration & 10 & 7 \\
Comparison of the effectiveness of traditional and western & 5 & 3 \\
$\quad$ medicine & 5 & 3
\end{tabular}




\begin{tabular}{lcc} 
Health-seeking behavior & 8 & 5 \\
Incorporation & 5 & 3 \\
Integration of traditional medicine & 13 & 8 \\
Knowledge & 5 & 3 \\
Marketing & 5 & 3 \\
Medical plant & 8 & 5 \\
Medicine & 13 & 8 \\
Perception & 25 & 17 \\
The use of traditional medicine & 25 & 17 \\
\hline
\end{tabular}

Table 2.

Continents and Countries Studied $(n=140)$

\begin{tabular}{lcc}
\hline & Number & Percentage \\
\hline Continent Explored & 49 & 35 \\
Africa & 68 & 48 \\
Asia & 2 & 2 \\
Caribbean & 2 & 2 \\
Europe and the UK & 14 & 10 \\
Latin America & 5 & 3 \\
North America & & \\
Most Observed Countries & 35 & 25 \\
China & 25 & 18 \\
India & 17 & 12 \\
South Korea & 14 & 10 \\
Nigeria & 13 & 9 \\
Hong Kong & & \\
\hline
\end{tabular}

Note: The total number of articles investigated for continents and countries researched is only 140 articles because more than ten articles are essays not presenting, specifically continents and countries studied.

research articles conveying obviously to test a theory.

To understand the framework and perspective used, the concepts applied by the scholars were reviewed in discussing traditional medicine policy. The ideas were broken down into four cohorts, as suggested by Timmermans (2003), as follows: institution, behavior, disease, and culture. The articles are classified as an institutional perspective if they examine the structure or political design and regulation or constitutional aspect of policy (North, 1990; Ostrom, 2011; Shirley, 2008). For this study's context, the behavior is defined as attitudes, actions, and responses drawn by the societies toward traditional medicine policy (Williamson et al., 2015; Yudiatmaja, Yudithia, Samnuzulsari, \& Suyito, 2020;
Yudiatmaja, Samnuzulsari, et al., 2020). Disease and medicine are articles discussing one or several diseases or medicines related to traditional medicine policy. Culture refers to all of the people's knowledge systems in interpreting their meaning to use traditional medicine (Sobiecki, 2014). These include the framework of culture, for example, trust, learning process, and transaction activities.

From the data in table 1 , we can see that the use of traditional medicine is the central topic studied by the articles reviewed. It can be possible because of the encounters of traditional medicine with the socio-cultural and global context. In the case of South Korea, the diverse and unequal interactions of Korean medicine, science, and industry have resulted, without reducing them to a single global justification or nucleus, in a 
concomitant production of new culture and power (Kim, 2009). In the case of African countries, post-independence and socialist visions had chosen traditional medicine for indigenous pharmaceutical companies, as well as promising greater freedom from global capitalism and multinational pharmaceutical companies (Langwick, 2015; Yudiatmaja, Yudithia, Samnuzulsari, Suyito, et al., 2020).

It is found that more than one-fourth (35 percent) of the articles provide behavior as the central point of the study, and 33 percent more articles focus on institutions. Predominantly, the articles use a single framework in analyzing traditional medicine policy. Regarding the articles' theory, the result reveals that much of the scholars (93 percent) only cite and discuss existing theory than examining or building a new theory ( 7 percent) for their foundational work. The theories cited are around pricing, healthseeking, and perceptions.

Evidence of this study indicates that there are diverse subjects studied by scholars when they explored traditional medicine policy. Nevertheless, there are several trends. As shown in table 1, perception and traditional medicine policy (17 percent) become the most common subjects studied by scholars. It is followed by the issue of attitudes and behavior (10 percent), integration and medicine ( 8 percent), and collaboration ( 7 percent). Another dimension of traditional medicine policy examined is the unit of analysis of the articles.

There is no surprise that the main topic studied by experts is a traditional medicine policy. These findings confirm Cardini et al. (2006) reviewing clinical research in traditional medicine. They found that the authors offered the following guidelines for selecting and prioritizing research therapies and creating study protocols. Traditional treatment assessments were best addressed first through collaborative, multinational, and comprehensive research. Protocols for the observational, prospective, pragmatic pilot study (randomized and controlled, where feasible) should be collaboratively designed and implemented simultaneously in the culture of origin and new contexts.

Data in Table 2 indicates that the most significant proportion studied by scholars is Asia (48 percent) in the study of traditional medicine policy. Meanwhile, Caribbean and Europe (including the UK) are only 2 percent. If it is detailed, China
(25 percent) and India (18 percent) are dominant countries investigated by scholars. These facts illustrate that most Asian countries' governments have concerned about traditional medicine over other regions in the continent. Therefore, the constellation of traditional medicine is still dominated by Asian countries, in particular, China, India, and South Korea.

China is a primary country in developing traditional medicine in the world since it is one of the origins of traditional medicine. As a consequence, traditional medicine in other countries, especially in East Asian countries, has a similar format to China. As emphasized by Park et al. (2012), China and Korea exhibited identical patterns in traditional medicine systems, while Japan exhibited various ways. Traditional medicine was practiced in a dual system with conventional medicine in China and Korea, and traditional medicine education was on average 6-year training programs for traditional medicine physicians, and full acupuncture, moxibustion, and cupping were insured. Whereas in Japan, conventional medicine was common, and traditional medicine was performed by each health care worker who received different traditional medicine education, respectively, and key traditional medicine therapies were partly insured.

Potential techniques of gathering the data areexisting orsecondarydata, interviews, mixed methods (survey and interview), and surveys. There are also several data sources, such as citizens, previous journals, patients, and practitioners. As seen in table 3, the interview is a common method used by scholars (38 percent). Concerning methods of analyzing the data, the findings show that qualitative analysis is most frequently used by the researchers ( 62 percent), and descriptive statistics is about 25 percent. The evidence helps us understand that the domination of the interpretive paradigm is still dominant in traditional medicine policy research. From the dimension of the source of data, this study finds that more than half of the articles are collected from the country's citizens. Households in the country represent citizens in the articles.

Although there were not many scholars involved in mixed methods, the rise in mixed methods shows that this method is currently being expanded. The use of mixed methods in social sciences is still becoming a critical 
discussion by academics. The scholars are still debating the emphasis of mixed methods in terms of the theory, methodology, design, and methodology (Creswell, 2009; Creswell \& Tashakkori, 2007). In terms of traditional medicine research, mixed methods propose new insight in the study of traditional medicine because it is still dominated by a single method. In addition, it can also corroborate mixed methods in social science research by providing such empirical evidence.

Another methodological aspect analyzed here is the sizes of samples and techniques for reaching them (see Table 4). Generally, most sample sizes commonly used are 2-9 respondents or informants (18 percent); another 16 percent employs 1020 respondents in their study. The smallest sample sizes are typically conducted by qualitative research, and the largest sample sizes are used by survey research (Yudiatmaja et al., 2017, 2018). Finally, the choice of sampling methods presents that more than half of the articles, 53 percent, conducts random sampling. The data draw that the researchers do not determine the respondents based on specific criteria.

The utilization of random sampling in traditional medicine research is related to the dominant method employed in the research, which is the qualitative perspective. This is a surprise because it is ordinarily used

Table 3.

Methods of Data Collection and Data Source $(n=140$ articles $)$

\begin{tabular}{lcc}
\hline Methodological Aspect & Number & Percentage \\
\hline Methods of gathering the data & & \\
Existing/secondary data & 33 & 22 \\
Interview & 58 & 38 \\
Mixed-methods (survey and interview) & 10 & 7 \\
Survey & 40 & 27 \\
Data source & & \\
Citizens & 79 & 57 \\
Journals & 19 & 13 \\
Official records & 12 & 8 \\
Patients & 12 & 8 \\
Practitioners & 19 & 13 \\
\hline
\end{tabular}

Table 4.

Sample Sizes and Methods $(n=140)$

\begin{tabular}{lcc}
\hline The Sample Size & Number & Percentage \\
\hline $2-9$ & 25 & 18 \\
$10-20$ & 23 & 16 \\
$21-40$ & 14 & 10 \\
$41-60$ & 12 & 9 \\
$60-120$ & 18 & 13 \\
$121-300$ & 15 & 11 \\
$301-950$ & 16 & 11 \\
$1.131-11.000$ & 12 & 9 \\
$>51000$ & 5 & 4 \\
Sampling methods & & \\
$\quad$ Purposive & 58 & 42 \\
Random & 75 & 53 \\
Snowball & 7 & 5 \\
\hline
\end{tabular}


in quantitative research. Even though in qualitative research, the sample size is not essential (Cleary et al., 2014; Samnuzulsari et al., 2019), the sample's adequacy quietly determines the results of the research. Although it excessively relies on the research objectives and method, much of the study uses a small sample involving two up to nine participants. Thus, in the future, the amount of sample should be increased to gain preferable analysis.

The findings of this study depict that a person is the majority of the scholars' unit analysis in examining traditional medicine policy. It is in line with the study of (Chang et al., 2007). The person has become a central analysis by scholars in exploring traditional medicine policy. Generally, in the number of articles, the person is positioned as an active subject determining the process of traditional medicine policy. The researchers usually explore the attitudes, behaviors, and knowledge of the person. For example, Lubega et al. (2010)Uganda, we conducted key informant interviews with staff at the pre-ARV clinic, focus group discussions with persons who looked after people living with HIV (PLWH study analyzing the reasons for the persons with HIV to dropout from pre-antiretroviral in Uganda. They suggested that the reasons cited for leaving pre-antiretroviral care include: insufficient guidance after the test due to lack of work by workers, pressure from alternative or spiritual treatments that are less stigmatic.

From the data present above (table 2), China, South Korea, Cuba, and India are dominantly a case study observed by the scholars. The results are quite different from the research of Eardley et al. (2012), finding European countries as the most countries studied in traditional medicine policy. Nonetheless, China, South Korea, and India have emerged as leading countries in traditional medicine because the government of these countries strongly concernsto develop traditional, complementary, and alternative medical (TCAM) system and integrates into their medical system (Josyula et al., 2016; Son, 1999; Wang \& Zhang, 2017)health systems, and the pharmaceutical industry, as well as patients and policymakers, which will leave a major impact on the practice of medicine. Interestingly, traditional Chinese medicine (TCM. In other words, there is no significant difference between traditional and Western medicine from the government perspective. Because of the complementary function, traditional and western medicine has been implemented simultaneously in various health care.

\section{Discussion}

Based on the explanation above, the research of traditional medicine policy comes from various areas of research. It still can be possible to be developed in the context of policy studies. In terms of policy studies, a number of scholars has claimed the policy as the process (Birkland, 2016; Hill, 2014; Howlett \& Ramesh, 1995). It consists of policy formulation, implementation, monitoring, and evaluation. In the future, the researchers have to apply at least one of all phases of the policy process in the research of traditional medicine policy.

So far, there is only a little attention to the scholars to investigate the aspect of the policy process. From the literature searched, several scholars have discussed the implementation (Guan et al., 2018; Macfarlane \& Alpers, 2010) and others have examined the evaluation of traditional medicine policy (Gavriilidis \& Östergren, 2012)and more broadly. Simple, transparent and acceptable tools are therefore required to evaluate policies from an empowerment perspective. In 2008, the South African Department of Health (DOHSA. Yet, the number of research by using the policy process perspective is tremendously little than the total articles founded. Might the scholars can explore the process of the formulation to obtain the formulating circumstances of traditional medicine policy in such a country.

In the further development, to extend the study of traditional medicine policy, the next research can be employed by using comparative studies, such as comparison either between eastern and western countries or between the successful country in developing traditional medicine policy and newly player country in the globe (Park et al., 2012). The researchers also can apply multiple frameworks such as institution, behavior, disease, medicine, and culture simultaneously in discussing traditional medicine policy. Even though the use of multiple concepts does not show good research, at least it can enrich our perspective in understanding traditional medicine policy in a different world.

The majority of the research on the 
policy of traditional medicine still utilizes a single method in reaching the issue. In the future, the scholars can use mixed-methods or multi-methodology by incorporating both qualitative and quantitative approaches to profoundly understand the phenomena (Greene et al., 1989; Palinkas et al., 2011). Besides obtaining a deep understanding of the complex events of traditional medicine policy, the use of mixed methods is worthy of seeking the phenomena deeply (Creswell, 2013). Traditional medicine policy occasionally involves many actors and interests in a political system. Practically, there are sometimes several tensions among the key players, as drawn by Cho (2000) and Kim (2009). The problem of traditional medicine policy is quietly dynamic. Thus, future research can also use a systems approach, such as systems dynamic (Maani \& Maharaj, 2004) or soft system methodology (Checkland, 1989; Checkland \& Poulter, 2010) in analyzing traditional medicine policy.

This study contributes to theory and practice, respectively. Theoretically, this study enriches the study of public policy, especially the issue of traditional medicine policy by providing an analysis of traditional medicine inquiries. By providing a literature review of traditional medicine policy, it also can add our knowledge in the issue of medicinal or health policy (Birkland, 2016). Practically, this study is worthwhile to the policymaker and implementer of traditional medicine policy all over the world. The results of this review can be obvious guidance for both policymaker and implementer in designing a decision regarding self-medication, natural remedies, dietary supplements, natural foods, robust foods, and phytoprotectants (Robinson \& Zhang, 2011)including herbal medicines, have been, and continue to be, used in every country around the world in some capacity. In much of the developing world, $70-95 \%$ of the population rely on these traditional medicines for primary care. $\mathrm{n}$ The global market for traditional medicines was estimated at US\$ 83 billion annually in 2008, with a rate of increase that has been exponential. $\mathrm{n}$ Regulatory status and the associated terminology varies widely. Traditional medicines are used as prescription or over-the-counter (OTC.

Several limitations of this study must be declared here. It can be a recommendation for future research in the same case. First, this study is conducted by systematic literature review. It only describes the trends and development of the articles on traditional herbal medicine policy qualitatively. There are various methods in the literature review (Cronin et al., 2008; Webster \& Watson, 2012). The subsequent studies should apply another method, such as systematic literature review (SLR), critical review, and bibliometric analysis. Second, most of the data in this study is obtained from the Scopus database. As recent evidence, the database from Scopus contains several errors than Web of Science (WoS) (Franceschini et al., 2016). Hence, the future study has to import the data from WoS to eliminate the errors. Third, this study does not use specific software in analyzing (Boell \& Cecez-Kecmanovic, 2010; Puks, 2016). To address the issue, future research can use various software available, such as Nvivo, Gephi, HisCite, Leximancer, etc.

\section{Conclusion}

The central purpose of this study is to identify the trends and development of the research of traditional medicine policy in the 150 scholarly journal articles. In conclusion, this study has demonstrated the variety of subjects, continents, countries, methods of data collection and sources of the data, and sample sizes and methods in gaining the sample. Through the analysis, we can understand the trends and popular development of the research of traditional medicine policy. This study also has a contribution to the policy practice of traditional medicine by highlighting the growth of traditional medicine studies.

\section{References}

Birkland, T. A. (2016). An introduction to the policy process: Theories, concepts, and models of public policy making (4th ed.). Routledge.

Boell, S. K., \& Cecez-Kecmanovic, D. (2010). Literature reviews and the hermeneutic circle. Australian Academic and Research Libraries, 41(2), 129-144.

Cao, H., Han, M., Li, X., Dong, S., Shang, Y., Wang, Q., Xu, S., \& Liu, J. (2010). Clinical research evidence of cupping therapy in China: A systematic literature review. BMC Complementary and Alternative Medicine, 10(1), 1-10.

Cardini, F., Wade, C., Regalia, A. L., Gui, S., Li, W., Raschetti, R., \& Kronenberg, 
F. (2006). Clinical research in traditional medicine: Priorities and methods. Complementary Therapies in Medicine, 14(4), 282-287.

Chang, H., Wallis, M., \& Tiralongo, E. (2007). Use of complementary and alternative medicine among people living with diabetes: Literature review. Journal of Advanced Nursing, 58(4), 307-319.

Checkland, P. (1989). Soft systems methodology. Human Systems Management, 8(4), 273-289.

Checkland, P., \& Poulter, J. (2010). Soft systems methodology. In M. Reynolds \& S. Holwell (Eds.), Systems approaches to managing change: A practical guide (pp. 191-242). Springer.

Cho, B.-H. (2000). The politics of herbal drugs in Korea. Social Science and Medicine, 51(4), 505-509.

Cleary, M., Hayter, M., \& Horsfall, J. (2014). Data collection and sampling in qualitative research: Does size matter? Journal of Advanced Nursing, 70(3), 473-475.

Creswell, J. W. (2009). Mapping the field of mixed methods research. Journal of Mixed Methods Research, 3(2), 95-108.

Creswell, J. W. (2013). Research design: Qualitative, quantitative, and mixed methods approaches (4th ed.). Sage.

Creswell, J. W., \& Tashakkori, A. (2007). Differing perspectives on mixed research methods. Journal of Mixed Research Methods, 1(4), 303-308.

Cronin, P., Ryan, F., \& Coughlan, M. (2008). Undertaking a literature review: A stepby-step approach. British Journal of Nursing, 17(1), 1-6.

Eardley, S., Bishop, F. L., Prescott, P., Cardini, F., Brinkhaus, B., Santos-Rey, K., Vas, J., von Ammon, K., Hegyi, G., Dragan, S., Uehleke, B., Fønnebø, V., \& Lewith, G. (2012). A systematic literature review of complementary and alternative medicine prevalence in EU. Forschende Komplementarmedizin, 19(Suppl 2), 1828.

Elfahmi, Woerdenbag, H. J., \& Kayser, O. (2014). Jamu: Indonesian traditional herbal medicine towards rational phytopharmacological use. Journal of Herbal Medicine, 4(2), 51-73.

Elo, S., \& Kyngäs, H. (2008). The qualitative content analysis process. Journal of Advanced Nursing, 62(1), 107-115.

Fink, A. (2014). Conducting research literature reviews: From the internet to paper (4th Ed.). Sage.

Fitzpatrick, J., Goggin, M., Heikkila, T.,
Klingner, D., Machado, J., \& Martell, C. (2011). A new look at comparative public administration: Trends in research and an agenda for the future. Public Administration Review, 71(6), 821-830.

Franceschini, F., Maisano, D., \& Mastrogiacomo, L. (2016). Empirical analysis and classification of database errors in Scopus and Web of Science. Journal of Informetrics, 10(4), 933-953.

Gavriilidis, G., \& Östergren, P.-O. (2012). Evaluating a traditional medicine policy in South Africa: Phase 1 development of a policy assessment tool. Global Health Action, 5(1), 1-11.

Greene, J. C., Caracelli, V. J., \& Graham, W. F. (1989). Toward a conceptual framework for mixed-method evaluation designs. Educational Evaluation and Policy Analysis, 11(3), 255-274.

Guan, X., Yang, M., Man, C., Tian, Y., \& Shi, L. (2018). The effect of the implementation of low price medicine policy on medicine price in China: A retrospective study. International Journal of Health Planning and Management, 33(3), e798-e806.

Hall, H. G., McKenna, L. G., \& Griffiths, D. L. (2012). Midwives' support for complementary and alternative medicine: A literature review. Women and Birth, 25(1), 4-12.

Hill, M. (2014). The public policy process (6th ed.). Routledge.

Howlett, M., \& Ramesh, M. (1995). Studying public policy: Policy cycles and policy subsystems. Oxford University Press.

Hsieh, H.-F., \& Shannon, S. E. (2005). Three approaches to qualitative content analysis. Qualitative Health Research, 15(9), 1277-1288.

Hunter, J., Leach, M., Braun, L., \& Bensoussan, A. (2017). An interpretive review of consensus statements on clinical guideline development and their application in the field of traditional and complementary medicine. BMC Complementary and Alternative Medicine, 17, 1-11.

Josyula, K. L., Sheikh, K., Nambiar, D., Narayan, V. V., Sathyanarayana, T. N., \& Porter, J. D. H. (2016). "Getting the water-carrier to light the lamps": Discrepant role perceptions of traditional, complementary, and alternative medical practitioners in government health facilities in India. Social Science and Medicine, 166, 214-222.

Kamsu-Foguem, B., \& Foguem, C. (2014). Adverse drug reactions in some African herbal medicine: Literature review and 
stakeholders' interview. Integrative Medicine Research, 3(3), 126-132.

Kim, J. (2009). Transcultural medicine: A multi-sited ethnography on the scientificindustrial networking of Korean medicine. Medical Anthropology, 28(1), 31-64.

Konisky, D. M., \& Teodoro, M. P. (2016). When governments regulate governments. American Journal of Political Science, 60(3), 559-574. https://doi. org/10.1111/ajps

Langwick, S. A. (2015). Partial publics: The political promise of traditional medicine in Africa. Current Anthropology, 56(4), 493-514.

Li, X., Yang, G., Li, X., Zhang, Y., Yang, J., Chang, J., Sun, $X_{\text {., }}$ Zhou, $X_{\text {., Guo, Y., }}$ Xu, Y., Liu, J., \& Bensoussan, A. (2013). Traditional Chinese medicine in cancer care: A review of controlled clinical studies published in Chinese. Plos One, $8(4), 1-11$.

Liu, J., Li, X., Liu, J., Ma, L., Li, X., \& Fønnebø, V. (2011). Traditional chinese medicine in cancer care: A review of case reports published in Chinese literature. Forschende Komplementarmedizin, 18(5), 257-263.

Lubega, M., Nsabagasani, X., Tumwesigye, N. M., Wabwire-Mangen, F., Ekström, A. M., Pariyo, G., \& Peterson, S. (2010). Policy and practice, lost in transition: Reasons for high drop-out from pre-antiretroviral care in a resource-poor setting of eastern Uganda. Health Policy, 95(2-3), 153158.

Maani, K. E., \& Maharaj, V. (2004). Links between systems thinking and complex decision making. System Dynamics Review, 20(1), 21-48.

Macfarlane, J., \& Alpers, M. (2010). National policy for an integrated health system and local implementation: The case of Papua New Guinea and the Nasioi. Human Organization, 69(4), 387-397.

Maroyi, A. (2013). Traditional use of medicinal plants in south-central Zimbabwe: Review and perspectives. Journal of Ethnobiology and Ethnomedicine, 9, 1-18.

North, D. C. (1990). Institutions, institutional change and economic performance. Cambridge University Press.

Oliver, S. J. (2013). The role of traditional medicine practice in primary health care within Aboriginal Australia: A review of the literature. Journal of Ethnobiology and Ethnomedicine, 9, 1-8.

Ostrom, E. (2011). Background on the institutional analysis and development framework. Policy Studies Journal, 39(1), 7-27.

Palinkas, L. A., Aarons, G. A., Horwitz, S., Chamberlain, P., Hurlburt, M., \& Landsverk, J. (2011). Mixed method designs in implementation research. Administration and Policy in Mental Health and Mental Health Services Research, 38(1), 44-53.

Park, H.-L., Lee, H.-S., Shin, B.-C., Liu, J.-P., Shang, Q., Yamashita, H., \& Lim, B. (2012). Traditional medicine in China, Korea, and Japan: A brief introduction and comparison. EvidenceBased Complementary and Alternative Medicine, 2012, 1-9.

Puks, R. (2016). Software tools for supporting literature reviews: An overview and a case study. Master Thesis in Tallinn University.

Riswan, S., \& Sangat-Roemantyo, H. (2002). Jamu as traditional medicine in Java, Indonesia. South Pacific Study, 23(1), $1-10$.

Robinson, M. M., \& Zhang, X. (2011). Traditional medicines: Global situation, issues and challenges. In The world medicines situation 2011 (Issue 3rd Edition).

Sabatier, P. A. (1991). Political science and public policy. PS: Political Science and Politics, 24(2), 144-157.

Sackey, E. K. A., \& Kasilo, O. M. J. (2010). Intellectual property approaches to the protection of traditional knowledge in the African region. African Health Monitor, 14, 89-102.

Saito, H. (2000). Regulation of herbal medicines in Japan. Pharmacological Research, 41(5), 515-519.

Samnuzulsari, T., Edison, E., \& Yudiatmaja, W. E. (2019). From popular to partisan public sphere: The political change of the coffee shops in Kepulauan Riau. Komunitas: International Journal of Indonesian Society and Culture, 11(1), 119-128.

Schulz, V., Hänsel, R., Blumenthal, M., \& Tyler, V. E. (2004). Rational phytotherapy: A reference guide for physicians and pharmacists. In Rational Phytotherapy (5th ed.). Springer-Verlag.

Shirley, M. M. (2008). Institutions and development. Edward Elgar.

Sobiecki, J.-F. (2014). The intersection of culture and science in South African traditional medicine. Indo-Pacific Journal of Phenomenology, 14(1), 1-10.

Son, A. H. K. (1999). Modernization of 
medical care in Korea (1876-1990). Social Science and Medicine, 49(4), 543550.

Takayama, S., Kaneko, S., Numata, T., Kamiya, T., Arita, R., Saito, N., Kikuchi, A., Ohsawa, M., Kohayagawa, Y., \& Ishii, T. (2017). Literature review: Herbal medicine treatment after large-scale disasters. The American Journal of Chinese Medicine, 45(7), 1345-1364.

Timmermans, K. (2003). Intellectual property rights and traditional medicine: Policy dilemmas at the interface. Social Science and Medicine, 57(4), 745-756.

Wachtel-Galor, S., \& Benzie, I. F. F. (2011). Herbal medicine: An introduction to its history, usage, regulation, current trends, and research needs. In I. F. F. Benzie \& S. Wachtel-Galor (Eds.), Herbal medicine: Biomolecula and clinical aspects (2nd ed., pp. 1-10). CRC Press.

Wang, W., \& Zhang, T. (2017). Integration of traditional Chinese medicine and Western medicine in the era of precision medicine. Journal of Integrative Medicine, 15(1), $1-7$.

Webster, J., \& Watson, R. T. (2012). Analyzing the past to prepare for the future: Writing a review. Management Information Systems Quarterly, 26(2), xiii-xxiii.

Weible, C. M. (2014). Introducing the scope and focus of policy process research and theory. In P. A. Sabatier \& C. M. Weible (Eds.), Theories of the policy process (pp. 3-24). Westview Press.

Weimer, D. L. (2008). Theories of and in the policy process. Policy Studies Journal, 36(4), 489-495.

Williamson, J., Ramirez, R., \& Wingfield, T. (2015). Health, healthcare access, and use of traditional versus modern medicine in remote Peruvian Amazon communities: A descriptive study of knowledge, attitudes, and practices. American Journal of Tropical Medicine and Hygiene, 92(4), 857-864.

World Health Organization. (2019). WHO global report on traditional and complementary medicine 2019. World Health Organization.

Yudiatmaja, W. E. (2012). Dinamika administrasi negara kontemporer: Konsep dan isu. Yogyakarta: Capiya Publishing.

Yudiatmaja, W. E. (2016). Implementasi dan evaluasi kebijakan publik. Tanjungpinang: UMRAH Press.

Yudiatmaja, W. E., Alfiandri, A., \& Hidayat, R. (2017). Far from fire: The service delivery quality gap plaguing Indonesian Ports. JKAP (Jurnal Kebijakan Dan Administrasi Publik), 21(1), 31-42.

Yudiatmaja, W. E., Edison, E., \& Samnuzulsari, T. (2018). Factors affecting employees' religiosity at the public workplace in Kepulauan Riau, Indonesia. Otoritas: Jurnal Ilmu Pemerintahan, 8(2), 143158.

Yudiatmaja, W. E., Samnuzulsari, T., Suyito, S., \& Yudithia, Y. (2020). Transforming institutional design in addressing sludge oil in Bintan seawater, Kepulauan Riau, Indonesia. IOP Conference Series: Earth and Environmental Science, 423(1).

Yudiatmaja, W. E., Yudithia, Y., Samnuzulsari, T., \& Suyito, S. (2020). An institutional analysis of the trans-national marine waste: A case study of sludge oil in Bintan seawater, Kepulauan Riau, Indonesia. IOP Conference Series: Earth and Environmental Science, 423(1).

Yudiatmaja, W. E., Yudithia, Y., Samnuzulsari, T., Suyito, S., \& Edison, E. (2020). Social capital of local communities in the water resources management: An insight from Kepulauan Riau. IOP Conference Series: Materials Science and Engineering, 771(1). 